\title{
As múltiplas faces da ciência no Brasil nos 100 anos após $A$ origem das espécies
}

\author{
The multiple faces of science in Brazil in the 100 \\ years following Origin of Species
}

\author{
Renan Springer de Freitas \\ Professor de Sociologia e Antropologia da Universidade federal de Minas Gerais \\ Rua Martinho Campos, 30/301 \\ 30310-140 Belo Horizonte - MG Brasil \\ springer@dedalus.lcc.ufmg.br
}

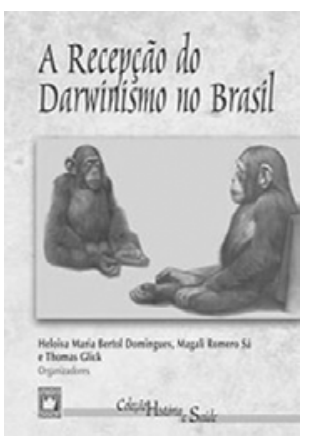

Heloisa Maria B. Domingues, Magali Romero Sá e Thomas Glick (orgs.)

A recepção do darwinismo no Brasil Rio de Janeiro, Fiocruz, 2003, 190p.
A recepção do darwinismo no Brasil reúne sete contribuições cujos títu los e autores serão apresentados ao leitor ao longo desta resenha. Devo mencionar imediatamente o que considero ser a principal contribuição do livro: mostrar as múltiplas faces da ciência que se produziu e se praticou no Brasil nos cem anos que se seguiram à publicação de $A$ origem das espécies - grosso modo - meados do século XIX a meados do século XX.

Inicio pela faceta mais tímida da ciência brasileira do século XIX: uma arqueologia, ou, mais propriamente, uma 'proto-arqueologia', praticada por engenheiros e cônsules alemães, que muitas vezes permaneceram anônimos. Digo 'proto-arqueologia' porque consistia tão somente na coleta e envio de informações aos centros mais avançados de produção científica da Europa. Deste tema ocupou-se o prof. Luis de Castro Faria, já nonagenário, em seu trabalho Virchow e os sambaquis brasileiros: um evolucionismo antidarwinista. Virchow (1821-1902), informa-nos o prof. Castro Faria, foi um dos mais famosos cientistas europeus do século XIX e criador do Museu de Antropologia de Berlim. Sambaquis, ensina-nos Thomas Glick, que assina a introdução do livro, são montes de conchas considerados restos de antigos assentamentos humanos. No século XIX eram considerados registros dos passados dos índios. Virchow nunca esteve no Brasil, mas fez discípulos que aqui residiam, e tinha enorme interesse pelos sambaquis de Santa Catarina. Ele queria saber se estes sambaquis eram formações naturais ou construídas intencionalmente pelos índios. Seus discípulos enviavam materiais como esqueletos e machados, além de relatórios minuciosos. O prof. Castro Faria deixa claro que do Brasil nada interessava senão tais informações. O trabalho analítico cabia todo ao próprio Virchow. Mas não somente estes quase anônimos alemães colaboraram com Virchow. Heloisa Maria Bertol Domingues e Magali Romero Sá, em sua contribuição: Controvérsias Evolucionistas no Brasil do Século XIX, informam que Virchow recebia também material de ninguém menos que o próprio Imperador D. Pedro II. D. Pedro II abastecia ainda, com fósseis de crânios humanos, um dos pais fundadores da antropologia craniométrica, Quatrefages, o grande adversário de Darwin.

Paralelamente a esta 'proto-arquelogia', desenvolveu-se, também, no Brasil da segunda metade do século XIX, uma antropologia craniomé- 
trica, praticada por uma elite de médicos e diretores dos museus de ciência do Império, cuja principal característica era a assimilação acrítica do darwinismo social no estabelecimento de hipóteses sobre a relação entre raça e desenvolvimento. Esta triste faceta da ciência brasileira nos é apresentada na contribuição de Lilia Schwarcz, O Espetáculo da miscigenação. Trata-se de um texto extraído de um texto maior, a tese de doutoramento da autora, $\mathrm{O}$ espetáculo das raças, já publicado como livro. Receio que seja necessária uma prévia leitura desse livro para a compreensão do argumento da autora. De minha parte, só consegui ter alguma compreensão ao ler a síntese do referido livro, a qual felizmente se encontra em outra contribuição, a de Regina Gualtieri. Retorno a ela oportunamente. Ao leitor que porventura não tenha lido O espetáculo das raças, sugiro ir antes à página 49 da Coletânea, onde se encontra a síntese de Gualtieri.

Nelson Papavero, Regina Cândida Ellero Gualtieri e Thomas Glick apresentam-nos um quadro da ciência brasileira que contrasta radicalmente com tudo o que ambos, o prof. Castro Faria e a profa. Schwarcz apresentaram. As contribuições desses autores documentam uma ciência biológica vigorosa, praticada no Museu Nacional do Rio de Janeiro, perfeitamente afinada com a biologia que então se produzia na Europa.

Papavero, no artigo Fritz Müller e a comprovação da teoria de Darwin, empenha-se em mostrar que a contribuição científica do migrante alemão Fritz Müller (1822-1897), radicado no Brasil desde 1852, em nada fica atrás da de Ernst Haeckel - a quem se credita o esforço pioneiro para articular a teoria da evolução por seleção natural com uma teoria do desenvolvimento embrionário. ${ }^{1}$ Haeckel tornou-se célebre por sua tese, tão amplamente conhecida, de que a ontogenia recapitula a filogenia. Papavero foi longe a ponto de dizer que "Haeckel utilizou as idéias de Müller, tornando-as as pedras angulares de sua embriologia evolutiva e dando-lhes uma formulação mais precisa e mais técnica, sem acrescentar nada de essencialmente novo" (p. 40). Tão ousada afirmação despertou minha curiosidade sobre se Ernst Mayr, em seu monumental The growth of biological thought, tinha algo a dizer sobre isto. De acordo com Mayr, Müller e Haeckel chegaram independentemente à mesma conclusão. Quem tem razão, Mayr ou Papavero? Não tenho como saber. Seja como for, não quero deixar sem registro a afirmação de Papavero, à página 32, de que “Müller foi o primeiro a criar uma filogenia séria, com base no estudo exaustivo de material vivo, ao contrário das especulações meramente teóricas e fantasiosas, como as feitas por Haeckel". Receio que "especulações meramente teóricas e fantasiosas" sejam mais importantes para a ciência do que nosso biólogo Papavero esteja disposto a admitir. Não obstante este ponto de discordância, o trabalho de Papavero tem o grande mérito de mostrar como foi possível, no Brasil do século XIX, fazer uma ciência de ponta.

\footnotetext{
${ }^{1} \mathrm{O}$ trabalho de Domingues e Sá, já citado, também documenta a importante contribuição de Müller. Ver páginas 99 e 100 da coletânea.
} 
O mesmo nos mostra Thomas Glick, em relação ao século XX, em sua contribuição: A Fundação Rockfeller e a emergência da genética no Brasil (1943-1960). O trabalho de Glick me fez pensar que dificilmente alguma área científica no Brasil será capaz de experimentar um progresso tão formidável quanto a genética experimentou no período por ele estudado. Um contraste com as ciências sociais será útil: embora haja uma proporção epidêmica de trabalhos que louvam, ainda que com justiça, a obra de Gilberto Freyre, o nome de Freyre dificilmente aparece em esforços de reconstrução da história do pensamento antropológico. Esforços dessa natureza parecem ser raros, $^{2}$ mas há um que cai como uma luva à presente discussão. Refiro-me ao trabalho de Derek Freeman, intitulado The debate, at heart, is about evolution (Fairburn e Oliver, 1996), no qual se discute a inserção do culturalismo anti-evolucionista de Boas no pensamento antropológico. Freeman procura mostrar a continuidade entre o trabalho de Boas e o de seus discípulos. Ora, sabemos que Freyre foi um dos discípulos de Boas. Que importância Freyre tem enquanto tal? Se há trabalhos discutindo isto, eu desconheço. Quem lê Freeman pode ser levado a crer que Freyre é um discípulo menor de Boas - pelo menos se comparado àqueles que são sempre lembrados como os 'grandes' discípulos: Edward Sapir, Margareth Mead e Ruth Benedict. O trabalho de Glick faz, em relação aos discípulos brasileiros de Dobzhansky, a saber, Brito da Cunha, Crodowaldo Pavan, dentre outros, o que ainda não se fez em relação a este discípulo brasileiro de Boas chamado Gilberto Freyre. Ele procura mostrar que esses brasileiros não são discípulos menores de Dobzhansky; que eles têm um papel importante na genética das populações, tendo tido seus respectivos nomes figurados ao lado do nome do grande mestre em publicações importantes. Desnecessário dizer que tal pujança não seria possível sem um vigoroso apoio institucional. Este veio da Fundação Rockfeller que, dentre outras coisas, permitiu que Dobzhansky passasse um ano sabático no Brasil e, depois, que por muitos anos consecutivos tivesse pelo menos um geneticista brasileiro no laboratório de Dobzhanski em Columbia.

Um quadro não tão auspicioso da produção científica brasileira mas, ainda assim, bastante animador, nos é apresentado por Regina Gualtieri na contribuição: $O$ evolucionismo na produção científica do Museu Nacional do Rio de Janeiro (1876-1915). Esta contribuição é, na minha opinião, a que mais faz justiça ao título da coletânea. Gualtieri nos oferece um belo panorama do que foi a produção científica no $\mathrm{Mu}$ seu Nacional em dois períodos, o da administração Ladislau Neto (18751893) e o da administração Batista Lacerda (1895-1915). Ao discorrer sobre a produção científica no primeiro período, Gualtieri oferece-nos uma esplêndida ilustração do que foi a "ciência normal" darwiniana nos anos que se seguiram à publicação de $A$ origem das espécies. Recomendo ao leitor uma leitura detida da página 58 do livro, na qual a autora descreve os mais variados temas 'miúdos' sobre os quais diversos na-

${ }^{2}$ Cabe citar Paiva (2002), que discute como o pensamento de Giberto Freyre pode se inserir em uma história do conceito de raça. 
turalistas brasileiros, incluindo-se evidentemente Fritz Müller, que permaneceu no Museu por 15 anos, se debruçavam, tendo a teoria da evolução esboçada no livro seminal de Darwin como pano de fundo. Nesse período de efervescência de estudos 'miúdos' sobre a origem e a função das características adaptativas dos organismos, uma ciência aplicada, voltada para questões locais - como a da agricultura brasileira - passou a ter um status periférico.

Entretanto, mostra Gualtieri, esta nítida "ciência normal" darwiniana não se fez mais presente no período posterior: 1895-1915. Se, no primeiro período, o pensamento evolutivo conduziu os naturalistas a temas como a procura de seres vivos que pudessem representar formas de transição entre dois grandes grupos, agora, o que se apresentava eram problemas práticos como a cura da febre amarela ou do beribéri. Claude Bernard e Pasteur, e não mais Darwin, eram quem agora ocupava o cenário. Por que este declínio de Darwin? Minha resposta seria: por um esgotamento provisório do paradigma darwiniano, coisa que acontece com alguma freqüência! Não é uma resposta muito boa, admito, mas a de Gualtieri também deixa muito a desejar. De acordo com ela, no período em que o pensamento darwiniano foi bem aceito, ele estava em algum grau contaminado pelo lamarquismo. Este último, ao postular a herança de caracteres adquiridos, concedia ao indivíduo um certo lugar na condução de seus próprios assuntos, e isto tornava o darwinismo mais palatável à sociedade brasileira. Entretanto, nos anos 1880 os estudos de Weismann sobre as células somáticas jogaram uma pá de cal sobre a tese dos caracteres adquiridos. "Purgadas dos mecanismos lamarquistas", diz a autora, "as teorias de Darwin perderam a flexibilidade original e se tornaram, aos olhos de seus críticos, mais dogmáticas" (p. 85).

Penso que tudo isto pode ter de fato ocorrido - o trabalho de Domingues e Sá, a propósito, de certa forma documenta isto, ao mostrar a ambigüidade de muitos naturalistas brasileiros em relação ao darwinismo. Ladislau Neto, por exemplo, procurou numa época aliar evolução e criação e, nos anos 1880, "pareceu esquecer sua especialidade em botânica e passou a dedicar sua atenção aos estudos arqueológicos" (Domingues e Sá, p. 111). Entretanto, receio que nada disto tenha relação com as transformações (nos conteúdos das produções científicas nos dois períodos sobre os quais Gualtieri se dedica) que Gualtieri tão bem descreve. Se levado às últimas conseqüências, seu raciocínio nos levaria a pensar que Darwin só pôde ser bem aceito no Brasil enquanto seu pensamento se viu contaminado pelo lamarquismo. Foi a conta de Weismann aprimorar o pensamento darwiniano, "purgando-o" da tese equivocada da herança dos caracteres adquiridos, para que os cientistas brasileiros passassem a lhe opor resistência. Isto me soa muito estranho. A própria Gualtieri afirma que "vários dos assuntos investigados nessa fase (período 1895-1915) eram similares aos desenvolvidos por grandes museus de história nacional europeus, não por simples coincidência, mas como parte do programa de trabalho estabelecido por Lacerda" (p. 72). Se é assim, o constatado refluxo da ciência normal darwiniana, no segundo período abordado por Gualtieri, não é um fenômeno especificamente brasileiro, não podendo, portanto, es- 
tar significativamente relacionado com alguma característica conservadora da sociedade brasileira.

Se Gualtieri documenta uma pungente "ciência normal" darwiniana, Domingues e Sá documentam a "ciência normal" digna de pena, a que Popper se refere em seu conhecido debate com Kuhn, tributária da antropologia craniométrica e da antropométrica francesa, cujos principais expoentes eram Paul Broca e o já citado amigo do Imperador, Quatrefages. Se bem entendi Domingues e Sá, os representantes brasileiros desta antropologia, notadamente os médicos Batista de Lacerda e Rodrigues Peixoto, limitavam-se a reiterar as teses poligenistas de Quatrefages, visando com isto legitimar a supremacia branca. Não perseguiam nenhuma questão em particular. Tratava-se, em síntese, de um quadro desolador. Convido o leitor a contrastar a ciência que se praticava no Brasil tal como documentada por Gualtieri nas páginas 62 a 68, ou documentada por Glick nas páginas 153 a 155, com a documentada por Domingues e Sá nas páginas 104 a 107. É um exercício que vale a pena ser feito. Como explicar essas diferenças? $\mathrm{O}$ fato de levantar tal questão, em si mesmo, já recomenda plenamente o livro.

Cabe-me, para encerrar, informar ao leitor que há na coletânea mais uma contribuição, de apenas oito páginas, de Thomas Glick, intitulada O positivismo brasileiro na sombra do darwinismo: o grupo Idéia Nova em desterro. Não me vejo capaz de dizer qualquer coisa de aproveitável sobre esta contribuição, além de que me pareceu bastante informativa. Devo também mencionar, uma vez mais, a introdução de Thomas Glick, que lança alguma luz sobre as contribuições do prof. Castro Faria e de Domingues e Sá, além de fazer uma interessante, embora brevíssima, discussão sobre por que a recepção do darwinismo no Brasil foi menos problemática do que em outros países católicos.

\section{REFERÊNCIAS BIBLIOGRÁFICAS}

Fairburn, M. e

Oliver, B. (eds.)

1996

Paiva, L. H. de 2002
The certainty of doubt: tributes to Peter Munz. Victoria, Victoria of University Press.

À margem do paroquialismo metodológico: Roquete-Pinto, Gilberto Freyre e história do conceito de raça.Tese de doutoramento, Belo Horizonte, Universidade Federal de Minas Gerais.

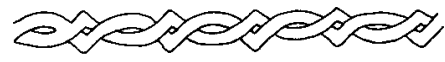

